\title{
Maneke as Local Wisdom in the Community of Small Islands in Sangihe Island Regency, North Sulawesi
}

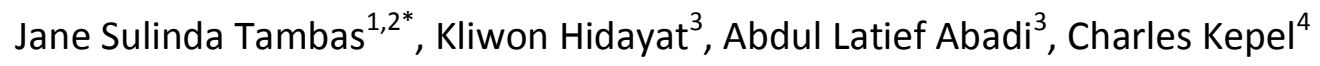 \\ ${ }^{1}$ Doctoral Program, Faculty of Agriculture, University of Brawijaya, Malang, Indonesia, \\ ${ }^{2}$ Sam Ratulangi University, Manado, Indonesia \\ ${ }^{3}$ Faculty of Agriculture, University of Brawijaya, Malang, Indonesia \\ ${ }^{4}$ Faculty of Fisheries and Marine Science, Sam Ratulangi University, Manado, Indonesia
}

\begin{abstract}
Maneke is one of the local wisdom in Sangihe Islands Regency, inherited from the ancestors of the people of Sangihe. Maneke contains the norms and values of life and customs to keep the mutual relationship between humans and nature. This local wisdom, however, has gradually become extinct. The aim of the research was to describe the Maneke as a local wisdom in Sangihe Islands. Sangihe Island Regency is one of a cluster of islands located in North Sulawesi province with 150 islands, 26 inhabited and 79 uninhabited islands. There are two islands on the cluster of uninhabited islands located in two Districts in Sangihe. The focus of this research is done on the Batunderang Island in the Subdistrict of South Manganitu and Para Island in the District of Tatoareng. This study used a qualitative approach to the design ethnography emphasizes the natural setting to see, learn, express and understand how to observe, and observations with in-depth interviews and conduct focus group discussions with community members, traditional leaders, public figures, figures from religious leaders and members of the implementation group of Maneke. Maneke is a socio-cultural system that has a socio-cultural elements contained in the components of the superstructure ideology, social structure and infrastructure material. Maneke is the component of the superstructure ideology because it has cultural values and norms into view, knowledge, activity and behavior patterns which are actualized in the traditions, customs, rituals beliefs or religion.
\end{abstract}

Keywords: local knowledge, Maneke, marine tourism, Sangihe Island.

\section{INTRODUCTION}

Local wisdom has been considered contributes significantly in local development. The existence of local wisdom for a long time causes people able to withstand a variety of environmental problems that happened. In many areas, however, local wisdom has been reported decrease and no longer exists in many communities. In Indonesia, local wisdom widely found and it has been reported contribute to the local community's life. The exploration of Indonesian local wisdom has been done to support sustainable development agendas.

Maneke is one of the local wisdom hold in Sangihe Islands. Maneke is passed down from the ancestors of the Sangihe people. It contains norms and values of life and customs to maintain a reciprocal relationship with the environment [1]. Maneke are rules which are agreed by the community in Sangihe with provisions regulating the ban to take and the permissibility of citizens in the use of natural resources and environment

\footnotetext{
${ }^{1}$ Correspondence address:

Jane Sulinda Tambas

Email : janesulinda@gmail.com

Address : University of Brawijaya, Veteran Malang 65145, Malang
}

within a specified period. The tradition of Maneke can be encountered in nearly all North West Nusa, another name of Sangihe Island. It is especially found in the small islands i.e. Bukide, Manipa, Batunderang, Bebalang, Kahakitang and Sitaro Islands.

Several studies have been conducted to see local wisdom Maneke, among others, the Sangihe towards public participation and implementation of Maneke [1]. Another study mentioned Local Wisdom Seke as a system for the results in terms of social and economic and community land rights in the sea of Sangihe Talaud [2]. Meanwhile, other study focused on customary rights and the environmental aspects of the activities of fishermen [3,4]. Research conducted by Akamichi and Mantjoro [5] is viewed in terms utilization and ocean management as well as some fishing gear are in some islands in the Sangihe and Talaud. In general, concepts and paradigms that they use in the studies mentioned above are centered on the notion of customary rights and the environmental aspects of the marine fishing activities.

Nowadays the existence of local wisdom is threatened by alien values which participated in through globalization. Globalization and 
modernization resulted in widespread information that can be accessed from different places and cultures in a society will impact the weakening of local wisdom, the weakening of local culture and social harmony fragility $[5,6,7]$. The success of the changes in rural communities is due to: (1) a rural community that has a tradition of strong kinship and cooperation so that they can easily share information and knowledge, (2) the rural communities are used to honor the next generation $[8,9]$. Local knowledge is also endangered because: (1) local knowledge is transferred by word of mouth, through rites and practices directly with the traditional method, while the next generation loss due to transfer media to better understand modern methods; (2) education programs that promote foreign values, science, language and history; (3) health programs that minimize the importance and effectiveness of traditional medicine; and (4) loss of land that separates the community from the environment associated with their knowledge and practices traditional foods [10]. Local knowledge is a heritage for generations that reflected the values of life are fused in the form of religion, culture and customs. It adapt to their environment, managing the environment wisely intangible knowledge, belief, understanding, tools, ethics, norms, customs, values of life, cultural values and activities to meet their needs $[4,11,12]$.

Local knowledge is the legacy of our ancestors in the values of life, which is fused in the form of religion, culture and customs. In the development of a community to adapt the environment, they develop intangible wisdom e.g. knowledge or ideas, tools, combined with traditional norms, cultural values, the activity of managing the environment in order to make ends meet [13]. Indigenous or local genius is the truth that a tradition, which is also a cultural identity as a philosophy, values, ethics, norms, beliefs, customs customary law, special rules and ways of behaving that institutionalized traditionally [14]. Knowledge of local or traditional (indigenous knowledge) is the ecological aspect in the form of a unique knowledge of the system of living and was instrumental on conservation. There is a community and a part of the local culture that does not sacrifice the interests of future generations $[7,12,15]$.

Recently, tourism has been considered as one of the new important economic earning among Sangihe Island dwellers. In such a case, the contribution of local wisdom is considered important. Maneke as part of the culture belongs to social institutions is important in natural resources and the environment resources management, especially for island as tourism destination. Based on the above discussion, this study is aimed to describe the conception of super structure of Maneke covering ideology, values and beliefs, social structure and infrastructure-related material of Maneke as local wisdom in Sangihe community views in the past.

\section{RESEARCH METHOD \\ Data Collection}

This study was conducted on October 2014 to May 2015. This research was conducted in two rural/island located in the district of South Manganitu namely Batunderang and Tatoareng Island. This study applied designed ethnography, namely close observation where researchers studied a cultural group in a natural setting in a specific time period with the collection of research data through observation. Observation and in-depth interviews were conducted to the members of the public in the study site [16].

\section{Data Processing and Analysis}

This research was conducted with a detailed analysis of the background conditions, the person, the subject of activities, as well as the places and events related to the focus of research. This study focused on describing the conception of Maneke which includes super structure in the form of ideology, values and beliefs, social structure and infrastructurerelated material as local wisdom in Sangihe community views in the past. Selection of key informants and informant conducted by the method of purposive and snowball sampling. In this snowball process, researchers will stop collecting this information from key informants if: (1) according to the researchers the information needed is enough, (2) if there has been a repetition of information by key informants about the same problems. These data include the place, actors, and activities.

The more detail dimensions include: (a) a room or area, based on their physical appearance; (b) the offender, everyone involved in the activities; (c) the activities, what people do in a given situation; (d) object, which is contained in the location of activities, (e) actions, all activities performed by an individual, (f) the event or events, which is a series of activities 
Maneke as local wisdom in the Sangihe Island Regency, North Sulawesi (Tambas, et al.)

carried out by individual people or groups of people, (g) time, which is a sequence of activities, (h) goals, which is something that is expected or will be achieved by the individual based on the meaning of his actions, and feelings, the emotions felt and expressed by someone.

Data and information is obtained from various sources, using multiple data collection techniques (triangulation). Collecting this information from key informants carried out continuously until saturated. The data analysis was also conducted simultaneously with data collection in the field.

\section{RESULT AND DISCUSSION \\ Sangihe Islands}

Sangihe is derived from the word sangi which literally is the daughter of heaven and ihe is gold. Tahuna domiciled in the capital and the overall number of islands in the archipelago numbering 105 islands with details, 79 uninhabited islands and 26 uninhabited islands. Small islands between Sulawesi and the Philippines inhabited by a group of people called Tribe of Sangir (Sangihe) Talaud. Sangihe Talaud community leaders said that once the tribe Sangihe Talaud come from some migrant groups into one tribe named Sangihe Talaud.

Sangihe Islands Regency is located between the islands of Sulawesi and Mindanao (Republic of the Philippines). In general, the average air temperature per month was $27.3^{\circ} \mathrm{C}$.

\section{History of Maneke}

Maneke which comes from the word Seke in the local language means meliwung Sangihe is an expression commonly used by the local community while going fishing. The other word of Maneke is Meliwung Kina or fishing, as expressed by Opolao/Kapitalaung (village head) of the island. Maneke on the island is also called the community with Kalase. Maneke also means Mahi Maneke: let's do and admit. Maneke also has social significance as the proverb ancestors of Batunderang namely Maneke Kina, Maneke Taumata which means that people fishing, or collecting. This was disclosed by Kapitalaung (village head) of Batunderang Island.

At the time of Maneke, community must admit that to catch scad fish (Decapterus sp.) using a tool called fish float or fish gutter is very simple and environmentally friendly. Ingredients and how to make laden with traditions and customs that predate the manufacture must be admitted. According to the elders of Sangihe, the development of fishing tackle were once only made of palm leaves that spun on a rope from Seho tree (palm tree/Arenga pinata) and then assembled in such a way to link the two ends above the water and pulled to shore. In these circles, there are a lot of fish that will be distributed throughout the local community. This can be seen in Figure 1.

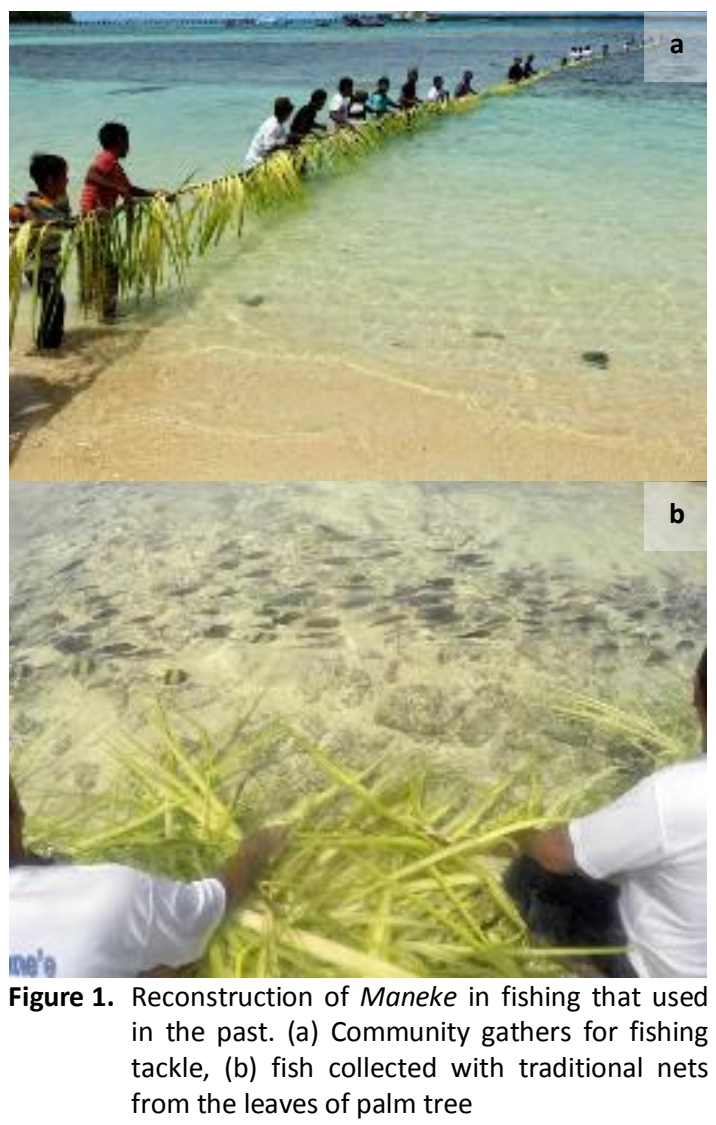

Seke is a simple fishing equipment and has peculiarities. Said to be strange because only by the size of the $95 \mathrm{~cm}$ tall bamboo and approximately $35 \mathrm{~m}$ long bamboo (Pandihe) and then released in the sea coral at a depth of 8 to $10 \mathrm{~m}$, can catch Malalugis/gutters/Kite fish (Decapterus macrasoma) and Dolosi/Tahumang/ Lolosi fish (fish with a yellow tail). Besides using tool, Maneke habits that performed before using the tool Pandihe is reading of spells to collect or call the fish. Thus the fishing catches a lot of fish and complies with eha/peliie and hope for an easier or smooth implementation of Maneke. Likewise, the way the distribution of fish, is for the whole community on the island.

The Concept of Maneke on Sangihe Community

Different ways of describing various sociocultural systems has been proposed by 
scientists. In this study, the basic components of the socio-cultural system are:

1. ideological superstructure consisting of the ideology of social values and cultural, religious/faith/religion, knowledge and norms

2. The social structure that consists of the presence or absence of social stratification, e.g. the division of labor

3. Infrastructure material consisting of technology, infrastructure, and economy (sharing)

\section{Maneke as Superstructure Ideology}

Maneke for Sangihe Community expressed by key informants and sources is seen as the values and norms of social and cultural, ecological and economic. Maneke is implemented in a pattern of behavior for a living, socializing, connecting with the community and the natural environment and in belief/faith/religion they believe to compliance with the God Almighty. Maneke also seen as a social value and present the sense of togetherness, unity, deliberation and consensus, bear the same problems as a community in order to achieve harmony and prosperity in life together in the community. As said by informants and key informants that Maneke is an awareness, and attitudes of their responsibilities, in preserving the ecological value of nature and the environment. Maneke give them the knowledge and awareness that the environment is essential to human survival. Therefore, they must take care to preserve and safeguard the environment, and human activities should be accompanied by a sense of responsibility towards nature and the environment, towards fellow human beings and towards the God Almighty.

The key informant said that with Maneke many restrictions and rules become the norms in behavior to maintain order, not to damage the environment with excessive resource extraction. Others also said that in Maneke many things become peliie/eha which should not be violated and later if breached will result in bad things happening within themselves as well as everyone in the village.

Eha or peliie is Sangihe local wisdom in the form of restrictions/ban or environmental ethics rules for public and Sangihe community. Eha is a hereditary habit among the people Sangihe form to pick crops and seafood when it's time to take that done before Maneke [1]. In Maneke have various rules that must be followed and done so it will go well and succeeded in catching fish as livelihoods. The rules in the form of prohibition and must be done at the time of making the tool Maneke or when fishing or after Maneke has been completed. The rules and ways of making Maneke tools are includes: (1) choose/lift tonaseng, (2) cutting wood (menuwang kauang), (3) Memepi bala/cut ruyung/Nibong, (4) Medea Bulo/find bamboo, (5) Mengandong Re: roll or spin the rope of palm, (6) Meluwu: cutting and splitting up to whittle rattan, (7) Make elise (mengelise), (8) Menemi: tuck coconut leaves (leaf) on the ropes, (9) Loading into the boat kengkang (mengengkang), and (10) perform Maneke sea fishing.

On the superstructures ideology, Maneke passed down by ancestors of Sangihe community hundreds of years ago with its traditions. It is contains the philosophy, values and norms, ethics contained in stages of Maneke and how to behave in society in doing Maneke, before Maneke and after Maneke done. These traditions are inherited from the past to the present. Traditions should be passed on and used as a guide in the move and behave in society. This is realized in the society of past Sangihe who look and make conception of Maneke as values, norms in all activities of the community in the past. These traditions contain cultural values and beliefs actualized in rituals performed in conjunction with local knowledge Maneke, whether it is done before, during or after Maneke to enjoy the fruits of success of the Maneke. Local wisdom of Maneke practice's success lies in the obedience and regularity of the stages in the implementation of which has been reduced during the Maneke hereditary. Obedience and adherence to the eha, mapeliie/ peliie as norms, planning Maneke carefully until execution will produce a catch as much as expected by the community. Violations and irregularities stages of Maneke and the lack of cohesiveness and unity causing the results are not as expected.

\section{Maneke as Social Structure}

In the social structure, organization of Maneke or Seke group as an organization in which people have the motivation and purpose together that enjoy a balanced life without any distinction. The organizational structure of Maneke has stratification and division of labor in doing Maneke led by Tonaseng. Tonaseng that being responsible are positioned with the highest status and role in Maneke by society and in 
Maneke as local wisdom in the Sangihe Island Regency, North Sulawesi (Tambas, et al.)

everyday life. Tonaseng make the decisions related to Maneke and the village head (opo lao) helps in deciding which should and should not. In Maneke, position of Tonaseng as a leader and in charge is higher than opolao or village head $[1,6]$.

The daily life of Sangihe community in the past, looked and sat Tonaseng, indigenous elders, traditional leaders in high-status positions in the community. The highest stratification of society occupied by Tonaseng (the leader of Maneke) must lead the group and their activity in the form of Maneke. The group consists of leaders and members of the board who have each task in preparing, implement and sharing the Maneke. As proposed by key informants and informant that Tonaseng is highly respected and get a high position in the community because of its supernatural powers and authority in leading the community earn a living in Maneke.

Tonaseng is the designation for maneke leader who has the task to collect or gather, organize and plan ways to manufacture and regulate fishing techniques, gave the command in Maneke, using the tool, and divide the result Maneke. Tonaseng karuane or assistant of Tonaseng help Tonaseng and set lekdeng or member of Maneke in duty at the time and in the preparations before Maneke. Tonaseng assistant is also has knowledge of the sea and supernatural knowledge. A secretary called Mindoreng are also responsible for the distribution of the fish (Fig. 2)

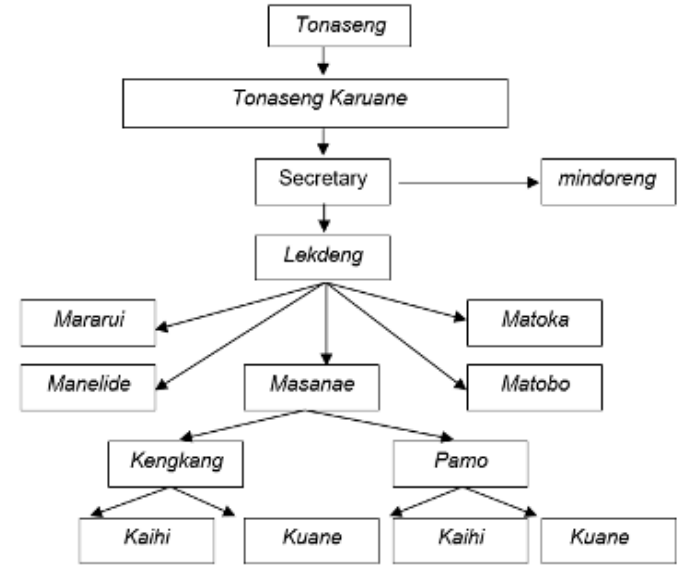

Figure 2. The Organizational Structure of Maneke/Seke

Secretary (also called Mindoreng, the person who shared the fish) and treasurer along with several members will count the catch, and a Mindoreng will command the division in several (four to five) members are in charge of distributing the fish to the relevant after the distribution is calculated. Lekdeng is Maneke members consisting of young and strong people by using kengkang boat with pandihe and ropes to pull pandihe as well as in the pamo boat. Lekdeng have served on the kengkang boat, on left (kaihi) and right (kuane), as well as at the pamo boat. Then there Mararui that will observe on the fish and fish flock position if it is at a location where pandihe be reduced or will get to that location. The organizational structure of Maneke can be seen in Figure 2 .

\section{Maneke as Material Infrastructure}

Tool equipment and technology of Maneke appliance consists of pandihe, elise and tuwo, assembled from materials that are environmentally friendly and have ecological values as well as in the release at the time of Maneke. It have philosophy and become a tradition, heritage from ancestors filled with noble values and norms that maintain the relationship between humans and the nature, human beings with each other and with the human creator. Manufacture of this equipment has a rule that has been patterned customary namely Pandihe. The right wing is all the leaf blade to the right, and left wing is all the leaf blade to the left of palm tree or leaf of young coconut plants (Cocos nucifera).

Piercing or menebi was last job as a sign that Pandihe has been created then held feasts salimbangu sehide (feast of thanks together) as a thanksgiving for Maneke equipment has been completed. The benefits of the leaf inserted on the bottom and top of the Pandihe is to keep the fish in it. Complete equipment Maneke consists of 1) Pandihe (kauang, bawalira, bulohoro, sasehide, laelisang, tuwo elise, talontong, ue/une, daluwo, saleni), 2) Elise, and 3) the boat consists of pamo and kengkang. Figure 3 is the Maneke tool.

Maneke in Batunderang and Para Island conducted twice in a day in the morning (dawn) at 04:30 am and in the afternoon at $17.30 \mathrm{pm}$ and the tool will be placed at a depth of $10-20 \mathrm{~m}$. Maneke facilities and infrastructure such as transport by using boats that are not machinepowered thus not pollute the environment and rowed so it does not interfere with nature and the environment. Location or point of Maneke which where the tool is released discussed in advance and carried out in rotation with its rules obeyed by all groups of Maneke. Violation of this will get sanctions. 

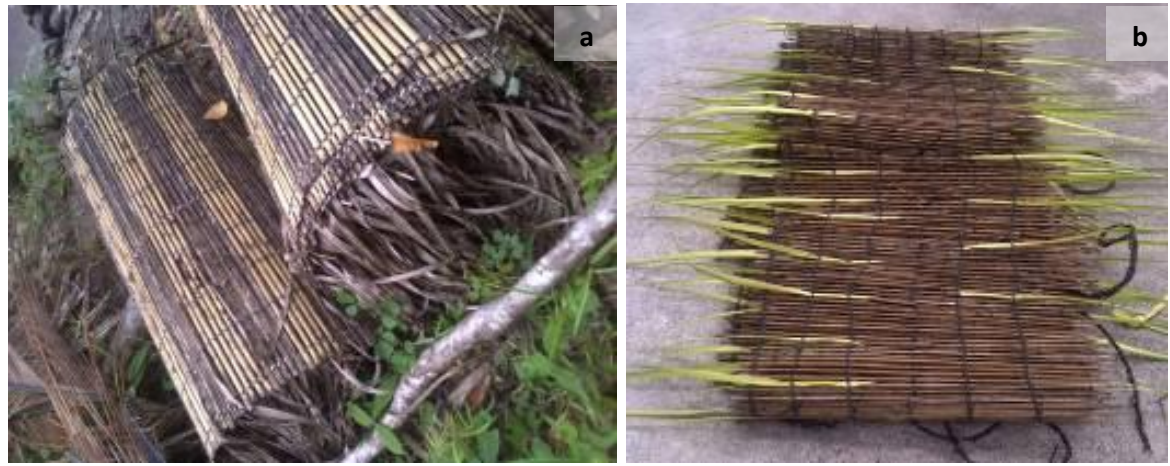

Figure 3. Tools for Maneke. a) used tools of Maneke and b) freshly made tools of Maneke

Explanation of a Tonaseng mentioned that to go Maneke, they put on five to six boats. One boat called pamo boat (type of boat) we also use one or two kengkang boats (canoe boat-size) and three londe boats (small outrigger canoe). Pamo boat use to accommodate the fish. Kengkang boat and londe boat is for the pandihe and used by fishermen who served as metelide or bamboo rod holders (telide) in each end of pandihe. In addition to being the major reservoir of the catch, pamo boats also serves as a command boat because therein the Tonaseng located. Tonaseng karuane or assistant of Tonaseng were on the kengkang boat that brought the pandihe. Sometimes Patoka loaded on the kengkang boat or also in the pamo boat. There are fishermen who served as mamatoka or position that held the bag of fish at the end of pandihe.

In the distribution of results, maneke have social values, solidarity, mutual help for the welfare and survival of one another, as reflected in division. It results Maneke prioritizing social value of the economy. Results of Maneke will be distributed to all the people who are live in the island, although the group that conducted the Maneke consists only of several members of the village. The locations of the Maneke were rotated in several hamlets, but the Maneke still done by only one group.

The first distribution of the catch is given to the orphans, the elderly and people with disability. After the first distribution is completed, it was given to widows, widowers, community leaders, traditional leaders, religious leaders, teachers, nurses and the public. Then the last will be distributed to members of Maneke, Tonaseng and administrators groups/ organizations of Maneke as described earlier.

According the explanation on the catch distribution, local knowledge of Maneke has a sublime value in arranging the life together for the various aspects of the social, cultural and economic as well as ecological aspect.

\section{Implication for Tourism Development in Small Islands}

The local wisdom is important in tourism destination management. It is especially important as an instrument to implement sustainable tourism practices. Indigenous knowledge and local wisdom has been indentified contributes to numerous aspect to increase destination sustainability and competitiveness. In Bali, it is observed that local wisdom contributes to the cultural landscape preservation, which is important in tourism industry. Local knowledge also contribute to the flora conservation along tourism corridor, and therefore increase scenic beauty of tourism corridors [17]. Local wisdom also contributes to the tourism governance observed in coastal tourism development in south Malang Regency.

Sangihe Island has opportunities in tourism development. The geographic position of Sangihe in North Sulawesi provides opportunities for ecotourism development, with Bunaken as a magnet for tourism development [18]. Maneke provides many positive aspect for the future tourism planning and development in Sangihe. Maneke able to be promotd as a cultural attraction, in which it has potential value to be presented to the visitors. The recreational use of environmental resources requires the provision of community with its local wisdom. These will ensure the sustainability of tourism practices.

Marine should be considered as important resources in tourism development. Water area are subject to various recreation activity, and therefore it is important to protect water environment from numerous potential threats. 
Maneke as local wisdom in the Sangihe Island Regency, North Sulawesi (Tambas, et al.)

The local wisdom actually not only contribute to the protection, but also serve the potential cultural attraction for visitors. This makes Maneke extremely suitable for tourism development.

\section{CONCLUSION}

Maneke is a socio-cultural system that has a socio-cultural elements contained in the components of the superstructure ideology, social structure and infrastructure material. Maneke is the component of the superstructure ideology because it is has cultural values and norms into view, knowledge, activity and behaviour patterns. These are actualized in the traditions, customs, rituals of beliefs/religion, rules existing at the time of preparation, practices and after Maneke. Necessity and prohibition/taboos also exist in Eha/peliie/teliing to maintain the relationship between man and his creator, the human and the natural environment and human beings with each other.

Maneke is a component of the social structure in a socio-cultural system that has elements of social stratification and division of labour. It is actualized in the structure of the organization or group structure of Maneke/Seke. Local wisdom Maneke as an infrastructure component material is an equipment and technology as well as the people's livelihood in the economic system that materialized in equipment of Maneke. Activity of the community who live and work in the small islands in the Sangihe Islands Regency in fishing exclusively hereditary derived from a common ancestor of Sangihe community. Maneke have socio-cultural nature or socio-religious uniqueness and rich in wisdom.

Maneke has potential to be developed as tourism attraction. The main problems related to the involvement of Maneke in tourism programs is the limitation skill of human resources in tourism development. It is especially common in developing countries. In such a case, important program are increasing human resources development. There are urgency needed for social and cultural empowerment. It is especially required to continue the local wisadom of the community in Sangihe. Tourism is the new stimuli to Maneke preservation.

\section{REFERENCES}

[1] Tambas, J. 2001. Public participation in environmental conservation through
Maneke on small islands in District of South Manganitu, Sangihe Talaud. Master Thesis. Sam Ratulangi University. Manado.

[2] Wahyono, A., Sudiyono, F. I. Tufail. 1993. Social and cultural aspects of maritime society, Eastern Indonesia. Sea Land Rights Village of Para, District Manganitu, Sangihe Talaud. Research Series PMB / LIPI 4/1993.

[3] Adhuri, D. S. 1993. Sea land rights and community dynamics fishermen in eastern Indonesia: a case study in Bebalang Island, Village of Sathean and Demta. Magazines Social Sciences Indonesia 20(1), 143-163.

[4] Wahyono, A. 1993. Changes flocking awareness at fishermen trawl (Purse Seine) in Sangihe and Talaud, North Sulawesi. Magazines Social Sciences Indonesia 20(1), 61-73.

[5] Akamichi and Mantjoro. 1996. Sea Tenur and transformation in The Sangihe Islands of North Sulawesi, Indonesia: The Seke Purse-Seine Fishery. Senri Ethnological Studies 42.

[6] Sartini. 2004. Digging local wisdom. Journal of Philosophy 37(2), 111-120.

[7] Mufid. 2010. Ethics and philosophy of communication. Kencana Prenada Media Group. Jakarta.

[8] Saharuddin. 2009. Empowerment of the poor based on local wisdom. Sodality: Transdisciplinary Journal of Sociology, Communication and Human Ecology 3(1), 17-44.

[9] Brookfield, H. 2008. Family farms are still around: time to invert the old agrarian question. Geography Compass 2, 108-126.

[10] Bernstein, H. 2013. Commercial agriculture in South Africa since 1994: natural, simply capitalism. Journal of Agrarian Change 13(1), 23-46.

[11] Tobin, B. 2004. Towards an international regime for protection of traditional knowledge: Reflections on the role of intellectual property rights. Paper presented at the Bioethical Issues of Intellectual Property in Biotechnology Conference, Tokyo, Japan. Available at: http://ipgenethics.group.shef.ac.uk/confere nce/papers/Tobin.pdf

[12] Keraf, S. 2006. Environmental ethics. Compass. Jakarta.

[13] Akhmar, A. M. and Syarifuddin. 2007 Revealing indigenous South Sulawesi. Regional PPLH (Environmental Research 
Center) Sulawesi, Maluku and Papua. Ministry of Environment Indonesia.

[14] Hadiwijoyo, H. 1980. Series history of western philosophy 2. Canisius. Yogyakarta.

[15] Berkes, F., J. Colding and C. Folke. 2000. Rediscovery of traditional ecological knowledge as adaptive management. Ecological Applications 10(5), 1251-1262.

[16] Creswell, J. W. 2010. Research design, approach qualitative, quantitative, and mixed. Student Library. Yogyakarta.

[17] Hakim, L., J. E. Kim and S. K. Hong. 2009. Cultural landscape and ecotourism in Bali Island, Indonesia. Journal of Ecology and Environment 32(1), 1-8.

[18] Newman, C. M., E. LeDrew. 2005. Towards community-and scientific-based information integration in marine resource management in Indonesia: Bunaken National Park case study. Environments- A Journal of Interdisciplinary Studies 33(1), 524. 